\author{
G. Kostyuk, O. Melkoziorova, E. Kostyuk, \\ Iyr. Shirokiy, Kharkiv, Ukraine
}

\title{
PROSPECTS FOR PRODUCING NANOSTRUCTURES IN THE VOLUME OF PARTS UNDER THE ACTION OF PLASMA FLOWS
}

\begin{abstract}
The paper presents the results of calculations of temperature fields and temperature stresses based on the solution of the unsteady joint problem of thermal conductivity and thermoelasticity. Zones of the material of the part were found where the conditions for the formation of nanostructures in the temperature range, rate of temperature increase, and maximum temperature stresses are realized. It is shown that under the action of nitrogen ions on steel, a significant region with nanostructures is obtained, while under the action of titanium ions on an aluminum alloy, this zone is limited. Under the action of electrons, nanostructures are not formed, temperature stresses in both cases have values of the order of $10^{8} \mathrm{~N} / \mathrm{m}^{2}$, they also do not make it possible to obtain nanostructures directly, while they can accelerate their production over the temperature range and their growth rate.
\end{abstract}

Keywords: nanostructured layers; temperature fields; temperature strains; nanoclusters; grain size; joint problem of thermal conductivity and thermoelasticity.

\section{Formulation of the problem}

Processing technologies using plasma flows are used in mechanical engineering, but the production of nanostructures was not theoretically predicted, but not experimentally studied.

All this says that the study of the possibility of obtaining nanostructures under the action of plasma flows is an important and timely task, since expanding the range of technologies for producing nanostructures gives prospects for increasing the physicomechanical characteristics of materials and increases the service life of parts [1-20].

This work was carried out within the framework of the program of the Ministry of Education and Science of Ukraine "New and resource-saving technologies in the energy sector, industry and the agro-industrial complex" (subsection 13 "Aerospace engineering and transport") on the topics: "Creation of physical and technical foundations for improving the quality of materials of aerospace structures" and "Development of the technological foundations of integrated technologies for plasma-ion processing of aerospace engineering parts "(subsection 6" Physical and technical problems of materials science"), "The concept created nanostructures, nano- and traditional coatings taking into account the influence of adhesion on the efficiency and performance of parts of AT, AD and CT", "Experimental-theoretical study of the production of nanostructures under the action of ion and light-beam fluxes on structural materials and CT", contractual works and cooperation agreements.

(C) G. Kostyuk, O. Melkoziorova, E. Kostyuk, Iyr. Shirokiy, 2020 


\section{Question Status}

In [16-19], the effect of grain size on the physicomechanical and electrical properties of materials was studied; in [16-18], the maximum microhardness was found to depend on grain size. In [17], a weak effect of grain size on microhardness of nitride in nc - TiN/ $\alpha$ Si3N4 magnetron nanocomposites at various annealing temperatures, whereas for vacuum-arc nanocomposites there are grain sizes for which maximum microhardness is realized.

In works [1-5], high microhardness values were obtained for a coating of $0,8 \mathrm{ZrN}+0,2 \mathrm{HfN}$ during combined treatment up to $45 \mathrm{GPa}$, an increase in wear resistance and resistance of a cutting tool up to 20 times, and when applying only a coating $0,8 \mathrm{ZrN}+0,2 \mathrm{HfN}$, microhardness amounted to about $35 \mathrm{GPa}$, which exceeds the microhardness of the individual components by more than 2 times, all this makes it possible to assume that even when coating is applied, the appearance of nanostructures is realized, while the additional electron beam modification will make it possible to obtain more efficient nanostructures with improved properties and at a considerable depth (up to $1 \mathrm{~mm}$ ).

Due to the action of ions of various sorts, energies, charges and electrons and their current densities, it is possible to maintain sufficient temperatures (due to the corresponding distribution of temperatures along the depth, a high average temperature is ensured), at the same time, choosing a location by depth (varying energies, charges and varieties of ions and electrons) provide high temperature gradients. Consequently, in a rather large volume of material, significant stresses will act, i.e. the conditions for obtaining nanocrystalline structures will be satisfied.

Therefore, having slightly modernized the model of the action of individual particles on structural materials $[1,10]$, we obtain a model that takes into account the necessary factors (in particular, the charge of the ion and the nature of their complex interaction in a rather large volume under consideration were not taken into account in the model) and the simultaneous action of electrons.

\section{Model of action of an individual ion and electron on a structural materia}

The interaction of charged particle flows and plasma flows with structural materials is associated with the implementation of a wide range of processes: collisional, thermophysical, thermomechanical thermo-fatigue, diffusion, thermochemical and plasma chemical, but there are currently no studies that take these factors into account and, moreover, their relationship. All these processes affect both the nature of heat transfer in the volume of the part and on the surface, therefore, consideration of these processes is necessary both in 
the energy balance in the elementary volume of the metal target and in heat transfer on the target surface, i.e. in boundary conditions.

\subsection{Heat balance in the elementary volume of a part}

The change in the amount of heat in a unit volume (the first term on the left side of the equality) is realized due to: moving the particle flux along the surface to be treated or moving the target relative to the plasma flow with a velocity $\vee_{\Pi}$ (second term), thermophysical processes: the influence on the heat transfer of the final heat propagation velocity (third term), thermal conductivity (first term on the right), displacement of the evaporation front (second term), melting (third term); collision processes: a volumetric heat source due to the action of an ion and an electron particle (fourth term), energy consumption for atomic displacement (fifth term); thermoelastic, thermoplastic and thermofatigue processes that determine the energy of deformation of an elementary volume material (sixth term); diffusion processes that determine heat transfer by diffusing material (seventh term); thermochemical processes associated with the implementation of chemical reactions between the target material and the bombarding ions or between the components of alloys and composite materials (the eighth term) and Lenz Joule heating due to current spreading (the ninth term for ion and electron fluxes) and the crystallization energy (last term).

$$
\begin{aligned}
& C[T] \cdot \gamma[T] \frac{d T(x, y, z, t)}{d t}+C[T] \cdot \gamma[T] \frac{\partial T(x, y, z, t)}{\partial y} \cdot V_{n}+ \\
& +C[T] \cdot \gamma[T] \cdot \tau_{p} \frac{d^{2} T(x, y, z, t)}{d t^{2}}=\nabla \lambda[T \cdot \nabla T](x, y, z, t)+ \\
& +C[T] \cdot \gamma[T] \cdot V_{T M} \frac{\partial T(x, y, z, t)}{\partial x}- \\
& -A \cdot L_{\bullet} \cdot \gamma[T] \frac{d V_{\bullet}}{d t}+B \cdot j_{i, e} \cdot \mu_{i, e} \frac{\partial E_{i, e}}{\partial x}-E_{, M} \cdot S_{, M} \frac{j_{i, e}}{\lambda_{c p i, e}} \pm \\
& \pm D \frac{d W(x, y, z, t)}{d t} \pm m_{a} \cdot C_{a}\left[T_{a}\right] \frac{d n_{a}}{d t}\left(T_{a}-T(x, y, z, t)\right)_{ \pm} \\
& \pm P_{T . X .}\left(n_{A}, n_{B}, T, t_{e},\right) \frac{d n_{A(B)}}{d t} L_{T, X, P}+\rho[T] \cdot j^{2}(x, y, z, t),
\end{aligned}
$$

where $\mathbf{C}[\mathbf{T}]$ and $\gamma[\mathbf{T}]$ are the specific heat and density of the target material corresponding to temperature $\mathbf{T}$;

$\tau_{p}$ - time of temperature relaxation by one Kelvin; it;

$V_{n}$ - the velocity of the plasma, electron or ion stream or target relative to 
$\boldsymbol{L}_{\text {Пл }}$ and $\boldsymbol{L}_{\text {T.X.P }}-$ specific heat of fusion and thermochemical reaction;

$V_{\phi}[T]$ - rate of displacement of the evaporation front;

$\boldsymbol{V}_{\boldsymbol{n} \boldsymbol{}}$ - volume of molten metal;

$\boldsymbol{j}_{i, e}-$ current density of ions, electrons or plasma flow;

$\boldsymbol{\mu}_{i, e}$ - coefficient of accommodation of an ion and an electron;

$\frac{\partial E_{i, \boldsymbol{e}}}{\partial \boldsymbol{x}}$ - energy loss of the ion and electron at the depth of the target;

$\boldsymbol{E}_{\boldsymbol{c} \boldsymbol{M}}$ - atomic displacement energy;

$S_{c m}$ - the number of displaced atoms as a result of the action of an ion or electron;

$\lambda_{c p i, e}$ - average linear mean free path of ions and electrons in the target material;

$w(x, y, z, t)-$ strain energy of a unit target volume;

$\boldsymbol{m}_{\boldsymbol{a}}$ - mass of a diffusing atom;

$\boldsymbol{C}_{a}\left[\boldsymbol{T}_{a}\right]$ - the heat capacity of the diffusing material at a temperature of $\mathbf{T}_{\mathbf{a}}$;

$\boldsymbol{P}_{T . X}\left(\boldsymbol{n}_{A}, \boldsymbol{n}_{B}, \boldsymbol{T}, \boldsymbol{t}_{\boldsymbol{B} 3}\right)$ - the probability of a thermochemical reaction, depending on the concentration of reagents $\boldsymbol{n}_{\boldsymbol{A}}$ and $\boldsymbol{n}_{\boldsymbol{B}}$, temperature $\mathrm{T}$ and interaction time $\boldsymbol{t}_{\boldsymbol{B} 3}$;

$\boldsymbol{n}_{\boldsymbol{A}}$ and $\boldsymbol{n}_{\boldsymbol{B}}$ - concentration of the reagent that determines the possibility of a reaction;

$\boldsymbol{\rho}[\boldsymbol{T}]$ - electrical resistivity at temperature $\mathrm{T}$;

$j(x, y, z, t)$ - current density taking into account current spreading.

$W_{\kappa p}$ - crystallization energy.

The energy of deformation of a unit volume is defined as:

$$
W=G\left[\begin{array}{c}
\varepsilon_{x x}{ }^{2}+\varepsilon_{y y}{ }^{2}+\varepsilon_{z z}{ }^{2}+2\left(\varepsilon_{x y}{ }^{2}+\varepsilon_{y z}{ }^{2}+\varepsilon_{z x}{ }^{2}\right)+ \\
+\frac{\mu}{1-\mu} \ell^{2}-\frac{2(1+\mu) \alpha_{1}}{1-2 \mu} \ell(T(x, y, z, t)-T)
\end{array}\right],
$$

where $2 \varepsilon_{i k}=2 \varepsilon_{k i}=\frac{\partial u_{k}}{\partial i}+\frac{\partial u_{i}}{\partial k}(k, i=x, y, z) ; \ell=\varepsilon_{x x}+\varepsilon_{y y}+\varepsilon_{z z}$,

$\varepsilon_{x x}, \varepsilon_{y y}, \varepsilon_{z z}$ - lengthenings;

$\varepsilon_{x y}, \varepsilon_{y z}, \varepsilon_{z x}$ - shifts relative to the corresponding axes;

$\boldsymbol{u}_{\boldsymbol{x}}, \boldsymbol{u}_{\boldsymbol{y}}, \boldsymbol{u}_{z}-$ movement relative to the corresponding axes;

$\alpha$ ! - coefficient of linear expansion of the target material;

$\boldsymbol{\mu}$ - Poisson's ratio (the ratio of lateral to longitudinal deformation, $\mu$ 
values are between 0 and 0.5 );

$\boldsymbol{G}$ - shear modulus (second-kind modulus);

$\boldsymbol{T}_{\boldsymbol{u}}-$ initial temperature. For iron $\boldsymbol{G}=3,5 \ldots .5,3 \cdot 10^{10} \mathrm{~N} / \mathrm{m}^{2}, \boldsymbol{\mu}=$ $0,23 \ldots 0,31$.

The shear strain $\varepsilon_{\mathrm{ik}}$ cannot be set arbitrarily, they are connected by differential relations - compatibility conditions:

$$
\begin{gathered}
\frac{\partial^{2} \varepsilon_{x x}}{\partial y^{2}}+\frac{\partial^{2} \varepsilon_{y y}}{\partial x^{2}}=2 \frac{\partial^{2} \varepsilon_{x y}}{\partial x \partial y} ; \\
\frac{\partial^{2} \varepsilon_{y y}}{\partial z^{2}}+\frac{\partial^{2} \varepsilon_{z z}}{\partial y^{2}}=2 \frac{\partial^{2} \varepsilon_{x y}}{\partial z \partial y} ; \\
\frac{\partial^{2} \varepsilon_{x x}}{\partial z^{2}}+\frac{\partial^{2} \varepsilon_{z z}}{\partial x^{2}}=2 \frac{\partial^{2} \varepsilon_{z x}}{x z} ; \\
\frac{\partial^{2} \varepsilon_{x x}}{\partial y \partial z}=\frac{\partial}{\partial x}\left[-\frac{\partial \varepsilon_{y z}}{\partial x}+\frac{\partial \varepsilon_{z x}}{\partial y}+\frac{\partial \varepsilon_{x y}}{\partial z}\right] \\
\frac{\partial^{2} \varepsilon_{y y}}{x y \partial z}=\frac{\partial}{\partial y}\left[-\frac{\partial \varepsilon_{z x}}{\partial y}+\frac{\partial \varepsilon_{x y}}{\partial z}+\frac{\partial \varepsilon_{y z}}{\partial x}\right] \\
\frac{\partial^{2} \varepsilon_{z z}}{\partial y \partial x}=\frac{\partial}{\partial z}\left[-\frac{\partial \varepsilon_{y x}}{\partial z}+\frac{\partial \varepsilon_{y z}}{\partial x}+\frac{\partial \varepsilon_{x z}}{\partial y}\right] .
\end{gathered}
$$

These conditions verify the correctness of the determination of elongations and shifts, and their correction by introducing additional stresses.

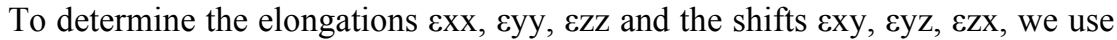
the expression of the thermoelastic displacement potential F.

$$
\begin{aligned}
& \Delta \Phi-\frac{1-2 \mu}{2(1-\mu)} \cdot \frac{\gamma}{G} \cdot \frac{\partial^{2} \Phi}{\partial t^{2}}= \\
& =\frac{1+\mu}{1-\mu} \cdot \alpha_{1} \cdot[T(x, y, z, t)-T,],
\end{aligned}
$$

where $\gamma$ is the density of the target material.

Given that the problem is solved in a moving coordinate system and upon reaching a stationary or close to it mode, the second term on the left side of equation (4) becomes insignificant, we obtain:

$$
\Delta \Phi=\frac{1+\mu}{1-\mu} \cdot \alpha_{1} \cdot[T(x, y, z, t)-T] .
$$


By the magnitude of the thermoelastic potential of displacements and by known relations we find the values of elongations and shifts:

$$
\varepsilon_{i k}=\frac{\partial^{2} \Phi}{\partial i \partial k},(i, k=x, y, z) .
$$

The magnitude of temperature stresses is determined by the expression:

$$
\sigma_{i k}=2 G\left(\frac{\partial^{2} \Phi}{\partial i \partial k}-\Delta \Phi \cdot \delta_{i k}\right),
$$

where $\delta_{i k}$ obeys the conditions: $\delta_{i k}=0$ at $i \neq k \quad(i, k=x, y, z)$ $\delta_{i k}=1$ at $i=k$.

In the seventh term of formula (1), which takes into account heat transfer by a diffusing material, the mass of a diffusing atom is defined as:

$$
\boldsymbol{m}_{\boldsymbol{a}}=\boldsymbol{M} \cdot \boldsymbol{m}_{\boldsymbol{p}},
$$

where $\boldsymbol{M}$ is the atomic weight of the applied material;

$\boldsymbol{m}_{\boldsymbol{p}}$ is the mass of the proton.

The change in the concentration of diffusing atoms per unit time can be determined for $t<t_{k}$ as:

At $\boldsymbol{t} \geq \boldsymbol{t}_{\boldsymbol{k}}$

$$
\frac{d n_{a}}{d t}=\frac{j}{e \cdot z \cdot \sqrt{\alpha \tau}},
$$

where $\boldsymbol{j}$ - the current density;

$$
\frac{d n_{a}}{d t}=\frac{j}{e \cdot z \cdot L_{D}},
$$

$\boldsymbol{e}$ - electron charge;

$z$ - charge number of the applied material;

$\boldsymbol{L}_{\boldsymbol{D}}$ - part thickness; $L_{D}^{2} / \alpha$

$\boldsymbol{t}_{k}$ - the time during which the part warms up to its entire thickness, $\boldsymbol{t}_{\boldsymbol{k}}=$ $\boldsymbol{\alpha}$ - thermal diffusivity coefficient.

The formula for calculating the diffusion coefficient:

$$
K_{\text {дu }}=a_{d} \cdot d^{2}{ }^{2} \cdot v_{o} \cdot \exp (-U /(k T)),
$$

where $\boldsymbol{a}_{\boldsymbol{d}}$ - factor of the order of 0.1 , determined by the type of crystal lattice;

$\boldsymbol{d}_{\boldsymbol{J}}$ - the distance between the nearest equivalent positions of vacancies in 
the crystal;

$V_{0}$ - a value of the order of the frequency of atomic vibrations in a crystal $\left(10^{12}-10^{14} \mathrm{~s}^{-1}\right)$;

$\boldsymbol{U}$ - the potential barrier that vacancies must be overcome when shifting to an adjacent position;

$\boldsymbol{k}$ - Boltzmann constant;

$\boldsymbol{T}$ - absolute temperature.

$\boldsymbol{q}_{\boldsymbol{n}}(\boldsymbol{x}, \tau)$ - the bulk density of the heat flux of radiation at a distance $(0,1, \delta)$ during the wear time $\tau, \delta=10^{-5} \div 10^{-4}$-the thickness of the layer in which the energy of ionizing radiation is absorbed, $1-\mathrm{R}$ is the absorption and $\boldsymbol{\alpha}$-the absorption coefficient.

\subsection{Heat transfer on the part surface}

The heat flux on the target surface is created due to:

1. Collision processes: heat generated on the surface due to the action of an electron or ion (first term on the right), heat flux with atomized particles (third term), with thermoelectrons (fourth term), for ions - heat flux with ionion emission or secondary ion emission (fifth term), potential ion-electron emission (sixth term), kinetic ion-electron emission (seventh term), characteristic x-ray radiation (eighth term), bremsstrahlung x-ray (ninth term), transition radiation (tenth term), for electrons heat is removed with secondary electrons (eleventh term), with secondary photons (twelfth term), with Cherenkov radiation (the thirteenth term), with transition radiation (the fourteenth term), with X-ray radiation (the fifteenth term), with the characteristic X-ray radiation (seventeenth term).

2. Thermophysical processes: the heat flux is removed with the vaporized material (the eighteenth term), with the left material in the liquid phase, if conditions are created for its emission (the nineteenth term), with the thermal radiation of the heated surface (the twentieth term) and with condensed atoms previously vaporized (twenty first term).

3. Plasma-chemical processes that occur due to reactions of a plasma stream or ion stream with atomized and vaporized target material or with adsorbiro radiation.

Energy is also transmitted through the emission of a stream of ions, electrons or plasma (last term) процессы при действии плазменного потока в широком диапазоне интенсивности потока частиц. 


$$
\begin{aligned}
& -\lambda[T] \frac{\partial T(x, y, z, t)}{\partial x}=F_{i, e}+q(r)-F_{p a c n}-F_{\text {м.э. }}- \\
& -\left[F_{\text {ии.е }}+F_{\text {и.ф.э }}+F_{\text {и.э.э }}+F_{\text {киэ }}+F_{x . p u}+F_{\text {трu }}+F_{\text {пu }}\right]_{i}- \\
& -\left[F_{\text {ве }}+F_{\text {вф }}+F_{u . \vartheta}+F_{n u}+F_{x . p u}+F_{m p u}+F_{\text {пил }}\right]_{e}- \\
& -F_{\text {исп }}-F_{\text {пл }}-\sigma \varepsilon T^{*}(0, y, z, t) \pm F_{\text {конд }}+F_{n x}+\sigma \varepsilon_{c} T_{c}^{*} \text {, }
\end{aligned}
$$

where $\boldsymbol{\sigma}-$ the Stefan-Boltzmann constant;

$\boldsymbol{\varepsilon}$ and $\boldsymbol{\varepsilon}_{c}$ - the degree of blackness of the surface of the target and the medium;

$\boldsymbol{T}_{\boldsymbol{c}}$ - medium temperature.

Let us consider in more detail each term in the formula (11):

The heat flux density due to the action of incident particles is:

$$
F_{i, e}=\mu_{i, e} E_{i, e} J_{i, e}-K_{o m p ~ i, e} J_{i, e} E_{o m p ~ i, e},
$$

where $\boldsymbol{\mu}_{\boldsymbol{i}, \boldsymbol{e}}$ - the coefficient of accommodation of an ion or electron, which determines the maximum fraction of energy that an ion or electron can transfer to an atom;

$\boldsymbol{E}_{i, \boldsymbol{e}}$ - energy of incident particles;

$\boldsymbol{K}_{\text {omp i,e }}$ - reflection coefficient of ions or electrons;

$\boldsymbol{E}_{\boldsymbol{o m p} \text { i,e }}$ - energy of reflected particles.

Knudsen defined the coefficient of accommodation as:

$$
\mu=\lim _{E_{1} \rightarrow E_{0}} \frac{E_{2}-E_{0}}{E_{1}-E_{0}},
$$

where $\boldsymbol{E}_{\boldsymbol{o}}-$ the energy of the incident particle;

$\boldsymbol{E}_{\boldsymbol{1}}$ - the energy of atoms on the surface;

$\boldsymbol{E}_{2}$ - the energy of the leaving particle; the remaining notation corresponds to 1 .

2. The results of the calculation of temperature fields and temperature stresses under the action of a plasma flow and the production of nanostructures

Thermophysical processes under the action of a plasma flow in a wide range of particle flux intensities are studied.

For individual particles $\left(j \leq j{ }^{\prime}{ }_{k p}\right)$ and flow as a continuous medium $\left(j \unlhd j{ }^{\prime}{ }_{K P}\right)$, the results presented in [1] can be used. The study will be carried out mainly 
for the case of the interaction of neighboring particles $\left(j<j{ }^{\prime}<j{ }^{\prime \prime}{ }_{K P}\right)$.

For individual particles $\left(j \leq j^{\prime}{ }_{k p}\right)$ and flow as a continuous medium $(j \leq$ $j{ }^{\prime}{ }_{K P}$ ), the above results can be used. The study will be carried out mainly for the case of the interaction of neighboring particles $\left(j<j\right.$ ' $\left.<j{ }^{\prime \prime}{ }_{K P}\right)$.

1. We consider three cases of thermal action of plasma on a part. The action of plasma flow particles as individual heat sources, i.e. the case of the absence of superposition of temperature fields of neighboring ions and electrons $\left(j \leq j^{\prime}{ }_{k p}\right)$.

2. The combined thermal effect of a number of particles upon application of their temperature fields $\left(j \leq j{ }^{\prime} \leq j{ }^{\prime \prime}{ }_{K P}\right)$.

3 . The effect of the plasma stream as a continuous medium $\left(j \geq j{ }^{\prime \prime}{ }_{K P}\right)$.

Consider the action of medium-energy electrons and ions in a plasma stream, provided that $j \leq j$ ' ${ }_{k p}$. If the current density lies between the first and second critical, i.e. when the superposition of temperature fields from the action of neighboring particles is observed, the task becomes more complicated. Let us analyze the effect of only four heat sources, the first two of which are ions with energy ii, and the rest are electrons with energy $\dot{E}_{i}$ (Fig. 4.1), and only a quarter of the energy of each of the four particles is released in the considered region.

This region is limited by a rectangular parallelepiped with sides equal to the distance between particles in the stream $l_{r}$ and a height equal to the maximum depth of penetration of the temperature field. Heat sources electrons - act at points $\mathrm{A}(0,0,0)$ and $\mathrm{C}\left(0,1_{\mathrm{r}}, 1_{\mathrm{r}}\right)$, while at points $\mathrm{B}\left(0,1_{\mathrm{r}}, 0\right)$ and $\mathrm{D}\left(0,0,1_{\mathrm{r}}\right)$ ions act (along verticals passing through these points).

In the general case, the consideration of temperature fields in the zone of action of the plasma flow was carried out at current densities equal to the first critical and at intermediate values. Such a consideration makes it possible to identify all extreme situations and assess the feasibility of dividing thermophysical problems by current densities (intensities) in the plasma stream.

In fig. 2 presents a picture of the temperature distribution in the zone of action on a part of iron (steel) of a plasma stream with nitrogen ions (average energy $\left.\dot{E}_{i}=800 \mathrm{eV}\right)$ and electrons $\left(\dot{E}_{e}=3 \mathrm{eV}\right)$ on the following surfaces:

1) $\mathrm{x}=0$; 2) $\mathrm{x}=0,75 \lambda_{c p}$; 3) $\mathrm{x}=1,5 \lambda_{c p}$

(where $\lambda_{-p}=1 / 2\left(\lambda_{H}+\lambda_{i}\right)$ in time

$$
t=\frac{\tau_{b i}+\tau_{b e}}{2}=\tau_{b c p}, \mathrm{t}=2 \tau_{b c p}, \mathrm{t}=10 \tau_{b c p} .
$$

The current densities in the plasma stream were:
$j=j{ }^{\prime}{ }_{k p}=7 \times 10^{6}$
$\mathrm{A} / \mathrm{m}^{2}$
(fig.
2 ,
a); $j=8 \times 10^{7}$
$\mathrm{A} / \mathrm{m}^{2}$
(fig. $\quad 2, b)$; 
$\boldsymbol{j}=\boldsymbol{j}{ }^{\boldsymbol{\prime}}{ }_{\mathrm{k} p}=0,3 \times 10^{8} \mathrm{~A} / \mathrm{m}^{2}$ (fig. 2, c).

It can be seen that at low current densities the temperature fields in the particle action zone remain the same as under the action of an ion with an energy of $800 \mathrm{eV}$ and an electron with an energy of $3 \mathrm{eV}$, the maximum temperature is observed in the ion action zone and amounts to $2100 \mathrm{~K}$, while in the action zone electron temperature is much lower. At the considered depths, the temperature distributions differ significantly; somewhat higher temperatures are observed at a depth of $0.75 \lambda_{c p}$. The temperature distribution over the studied surfaces is substantially inhomogeneous.

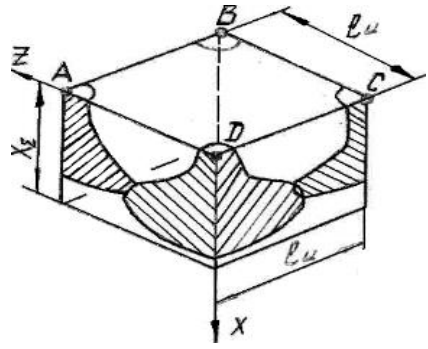

Figure 1 - A further increase in the current density to the second critical leads to an equalization of the temperature distribution

With an increase in the current density in the flow to $8 \times 10^{7} \mathrm{~A} / \mathrm{m}^{2}$, the superposition of the temperature fields of neighboring particles is observed; the nature of the temperature change in the studied planes becomes more uniform.

In the central part of the surfaces under consideration, the temperatures increase markedly, but the maximum temperature remains the same as in the previous case. However, in this case, temperature gradients are significant, and the nature of the temperature distribution at the studied depths is preserved (Fig. $2, b)$.

A further increase in the current density to the second critical leads to an equalization of the temperature distribution - they are approaching the maximum. An insignificant temperature gradient is observed along the diagonal where the electrons act (Fig. 2, c). A further increase in current density will lead to an equalization of the temperature distribution over the surface.

Under the action of a plasma flow on an aluminum component $\left(\dot{E}_{i}=800\right.$ $\mathrm{eV}, \dot{E}_{\boldsymbol{e}}=38 \mathrm{eV}$, titanium ions), the nature of the distribution of temperature over depth changes, their difference is observed. So, at a current density equal to the first critical $\left(j=j{ }^{\prime}{ }_{k p}\right.$, fig. 3 , a), there is a significant temperature heterogeneity along the depth of the target and in the studied planes. The nature 
of the distribution in the particle action zone is the same as under the action of ions with an energy of $800 \mathrm{eV}$ (the maximum temperature of $637 \mathrm{~K}$ is observed at depths $\mathrm{x}=0.6 \lambda_{c p}$ for ions). Significant temperature gradients are implemented. With an increase in the current density in the beam to $3 \times 10^{7} \mathrm{~A} /$ $\mathrm{m}^{2}$ (Fig. 3, b), some alignment occurs in the planes studied, its maximum temperature and its non-monotonicity in depth are preserved, and the gradients decrease compared to previous cases.

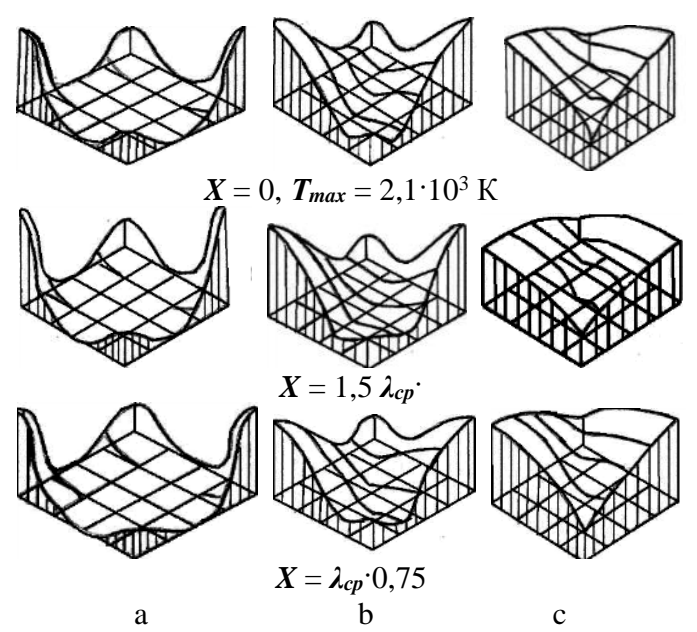

Figure 2 - Temperature fields in the zone of action of the plasma flow on iron / $\boldsymbol{E}_{c p}=800 \mathrm{eV}, \boldsymbol{E}_{c p l}=3 \mathrm{eV} /$ at various current densities:

$$
\begin{gathered}
\mathrm{a}-\boldsymbol{j}=\boldsymbol{j}_{\kappa \boldsymbol{\mu}}=7 \cdot 10^{6} \mathrm{~A} / \mathrm{m}^{2} ; \mathrm{b}-\boldsymbol{j}=8 \cdot 10^{7} \mathrm{~A} / \mathrm{m}^{2} ; \\
\mathrm{c}-\boldsymbol{j}^{\boldsymbol{I}{ }_{\kappa p}}=3.3 \cdot 10^{8} \mathrm{~A} / \mathrm{m}^{2}\left(\boldsymbol{T}_{\max }=2.1 \cdot 10^{3} \mathrm{~K} \text { nitrogen ions }\right)
\end{gathered}
$$

A further increase in the current density to the second critical one $(2.1 \times$ $10^{8} \mathrm{Am}^{2}$, Fig. 3, c) leads to equalization of the temperature distribution in the studied planes and their approximation to the maximum in the diagonal plane of electron action. Thus, an increase in current density leads to equalization of temperature fields.

After the completion of the irradiation cycle, leveling of temperature fields along the surfaces and a certain increase in temperature in depth are observed, after which it decreases. The study of temperature fields showed the presence of high temperature gradients, which indicates the possibility of realizing temperature stresses of significant magnitude. The results of the calculation of temperature stresses are presented in Fig. 4 and 5. So for the case of the action of a plasma flow with nitrogen ions $\boldsymbol{E}_{\boldsymbol{i}}=800 \mathrm{eV}$ and $\boldsymbol{E}_{\boldsymbol{e}}=3 \mathrm{eV}$ on 
iron, the maximum temperature stresses of $1.4 \cdot 10^{9} \mathrm{~N} / \mathrm{m}^{2}$ at a depth of $0.6 \boldsymbol{X}_{c p}$ are realized at a current density equal to the first critical $\left(7 \cdot 10^{6} \mathrm{~A} / \mathrm{m}^{2}\right)$ with increasing current density, a decrease occurs at current densities $j=8 \cdot 10^{6}$ and become very insignificant at current densities equal to the second critical density $\boldsymbol{j}=6.3 \cdot 10^{8} \mathrm{~A} / \mathrm{m}^{2}$. Moreover, for the first critical dense current, the temperature stresses on the surface reach $5.7 \cdot 10^{8} \mathrm{~N} / \mathrm{m}^{2}$, which decrease with increasing current density (Fig. 4).
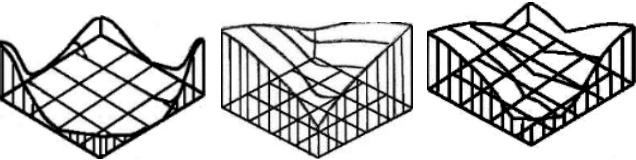

$X=0$
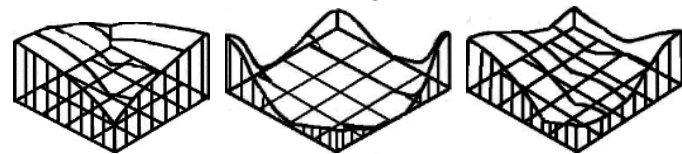

$$
X=0,6 \lambda_{c p}
$$
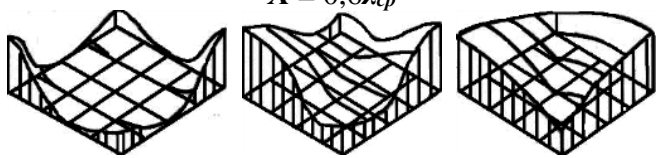

$$
\boldsymbol{X}=\lambda_{c p} 1,2
$$

a

$\mathrm{b}$

c

Figure 3 - The temperature fields on the surfaces $X=0, X=0,6 \lambda_{c p}$ and $X=1,2 \lambda_{c p}$ in the area of the plasma flow $\boldsymbol{E}_{\boldsymbol{i}}=800 \mathrm{eV}-\mathrm{Ti}, \boldsymbol{E}_{\boldsymbol{e}}=3.8 \mathrm{eV}$ with current density:

$$
\begin{aligned}
& \mathrm{a}-\boldsymbol{j}=\boldsymbol{j}^{I}{ }_{\kappa p}=2,7 \cdot 10^{6} \mathrm{~A} / \mathrm{m} 2 ; \mathrm{b}-\boldsymbol{j}=3 \cdot 10^{7} \mathrm{~A} / \mathrm{m} 2 ; \mathrm{c}-\boldsymbol{j}=\boldsymbol{j}^{I{ }^{\prime}}{ }_{\boldsymbol{k}}=3,7 \cdot 10^{7} \mathrm{~A} / \mathrm{m}^{2} \\
& \text { on an aluminum target } \boldsymbol{T}_{\max }=637 \mathrm{~K}
\end{aligned}
$$

In the case of a plasma flow with titanium ions $\boldsymbol{E}_{\boldsymbol{i}}=800 \mathrm{eV}$ and electrons, $\boldsymbol{E}_{\boldsymbol{e}}=3 \mathrm{eV}$ on an aluminum component with a current density equal to the first critical current density $\left(j^{I}{ }_{k p}=2.7 \cdot 10^{6} \mathrm{~A} / \mathrm{m}^{2}\right)$, the maximum values of thermal stresses are realized at a depth equal to $0.6 \lambda_{c p}$ and equal to $5.4 \cdot 10^{8} \mathrm{~N} / \mathrm{m}^{2}$ while at the same time on the surface and at a depth of $1.2 X_{c p}$ they are small.

The integrated effect of the plasma flow can be considered as for the case of the action of the particle flow as a continuous medium [1] but there the dynamics of temperatures and temperature stresses is substantially insignificant and high temperatures and temperature stresses should not be expected, and especially higher rates of temperature rise.

$$
\mathrm{N}^{+}+\mathrm{e}^{-} ; \boldsymbol{E}_{\boldsymbol{i}}^{A}=800 \ni \mathrm{B} ; \boldsymbol{E}_{\boldsymbol{e}}{ }^{\boldsymbol{c}}=3{ }_{\ni} \mathrm{B}
$$



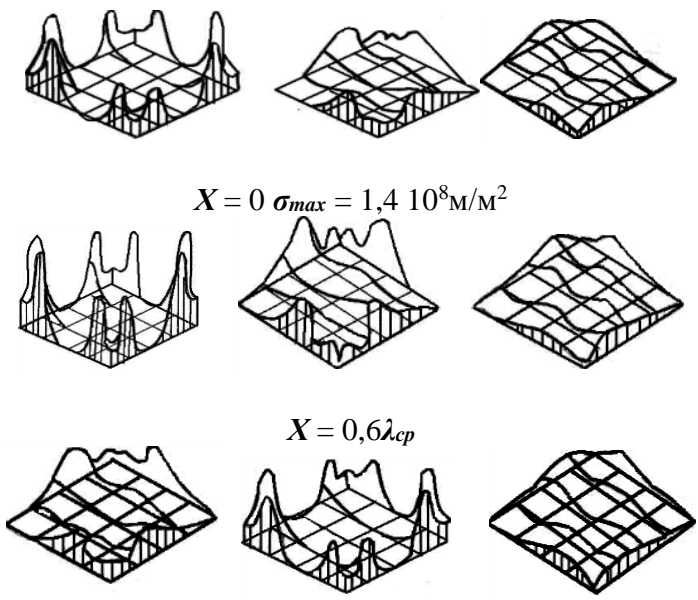

a

$$
X=\lambda_{c p} \cdot 1,2
$$

$\mathrm{b}$

$\mathrm{c}$

Figure 4 - Temperature stresses in the area of the plasma flow on iron (steel): $\boldsymbol{E}_{\boldsymbol{i}}=800 \mathrm{eV}, \boldsymbol{E}_{\boldsymbol{e}}=3 \mathrm{eV}, \boldsymbol{\sigma}_{\boldsymbol{n}}=1.4 \cdot 10^{9} \mathrm{n} / \mathrm{m}^{2} ; \mathrm{a}--\boldsymbol{j}=\boldsymbol{j}^{I_{k p}}=7 \cdot 10^{6} \mathrm{~A} / \mathrm{m}^{2}$ $\mathrm{b}-\mathbf{j}=8 \cdot 10^{7} \mathrm{~A} / \mathrm{m}^{2} ; \mathrm{c}-j^{I I}{ }_{\kappa p}=6.3 \cdot 10^{8} \mathrm{~A} / \mathrm{m}^{2}$
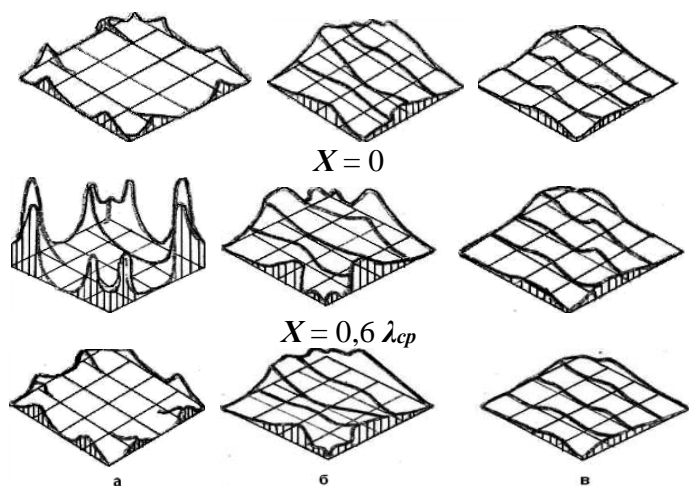

$X=\lambda_{c p} 1.2$

a

$\mathrm{b}$

c

Figure 5 - The fields of temperature stresses in the area of the plasma flow on molybdenum / $\boldsymbol{E}_{c p} 0800 \mathrm{eV}, \boldsymbol{E}_{c p l}=3 \mathrm{eV} /$ at various current densities: $\mathrm{a}-\boldsymbol{j}=\boldsymbol{j}_{\kappa \boldsymbol{k}}=2,7 \cdot 10^{6} \mathrm{~A} / \mathrm{m}^{2} ; \mathrm{b}-\boldsymbol{j}=3 \cdot 10^{7} \mathrm{~A} / \mathrm{m}^{2} ; \mathrm{c}-\boldsymbol{j}_{I \kappa k}=2,1 \cdot 10^{8} \mathrm{~A} / \mathrm{m}^{2}$,

$$
\sigma_{\text {max }}=5.4 \cdot 10^{8} \mathrm{~N} / \mathrm{m}^{2}
$$




\section{Conclusions}

It is shown that the required temperatures and rates of temperature rise are achieved, the temperature stresses (pressures) are sufficient to obtain nanostructures in the part volume, while at the same time, to increase the efficiency of this process, a small fraction of the catalyst ions can be supplied in the plasma stream.

It is shown that under the action of nitrogen ions on steel, a significant region with nanostructures is obtained, while under the action of titanium ions on an aluminum alloy, this zone is limited. Under the action of electrons, nanostructures are not formed, temperature stresses in both cases have values of the order of $10^{8} \mathrm{~N} / \mathrm{m}^{2}$, they also do not make it possible to obtain nanostructures directly, while they can accelerate their production over the temperature range and their growth rate.

References: 1. Kostyuk G.I. Physical processes of plasma-ion, ion-beam, plasma, light-beam and combined technologies. Physicotechnical foundations of coating, ion implantation and ion doping, laser processing and hardening, combined technologies [Text]: monograph. / G.I. Kostyuk. - Kyiv .: Publishing house of AINU, 2002. - 1038 p. 2. Kostyuk G.I. Effective cutting tool with a coating and a hardened layer [Text]: reference. / G.I. Kostyuk. - Kyiv .: Publishing house of AINU, 2003 .414 p. 3. Grechikhin L.I. Physics of nanoparticles and nanotechnology [Text] / L.I. Buckwheat. Minsk: UE Technoprint, 2004. - 397 p. 4. Kostyuk G.I. Scientific basis for the creation of modern technology [Text]: textbook. allowance / G.I. Kostyuk. - Kharkiv .: Nat. aerospace. University of them. NOT. Zhukovsky "KhAI", 2008. - 551 p. 5. Aksenov I.I. Vacuum arc in plasma erosion sources [Text] / II. Aksenov. - Publishing house of the Research Institute "KIPT", Kharkiv., 2005. 211 p. 6. Gusev A.I. Nanomaterials, nanostructures, nanotechnologies [Text] / A.I. Gusev. Moscow .: Fizmatlit 2005, 416 p. 7. Andrievsky R.A. Nanomaterials: concept and modern problems [Text] / R.A. Andrievsky // Physics of Metals and Metallurgy, 2003. - T. 91. - No. 1. - pp. 50 - 56. 8. Kostyuk G. I. Effective cutting tools with nanocoats and nanostructured modified layers: monograph-reference : in 2 books. / G. I. Kostyuk. - Kharkiv: Publishing house. Planet-print., 2016. - kN. 1. Plasma-ion and ion-beam technologies. - 735 p. 9. Kostyuk, G. I. Effective cutting tools with nanocoats and nanostructured modified layers: monograph-reference : in 2 books. / G. I. Kostyuk. - H.: Planeta-print, 2017. - kN. 2. Laser technology. - 507 p. 10. Kostyuk G. Prospects for designing the chemical composition of hardalloys, taking into account their hardening due to theformation of nanostructures [Text] / Kostyuk G.I., Popov V.V., Yevsieienkova H.V., Torosyan 
G.D. // Modern technologies in industrial production: VII All-Ukrainian scientific and technological conference, April 21-24. - Sumy city, 2020 - pp. 89-90.

\title{
Геннадій Костюк, Ольга Мелкозьорова, Олена Костюк, Юрій Широкий, Харків, Україна \\ ПЕРСПЕКТИВИ ОТРИМАННЯ НАНОСТРУКТУР У ОБ'ЄМІ ДЕТАЛІ ПРИ ДІЇ ПОТОКІВ ПЛАЗМИ
}

\begin{abstract}
Анотація. $B$ роботі представлені результати розрахунків полів температур $i$ температурних напружень на основі рімення нестаціонарної спільної задачі теплопровідності і термопружності. Знаходилися зони матеріалу деталі, де реалізуються умови утворення наноструктур. Розглядаємо три випадки теплової дї плазми на деталь. Дія частинок плазмового потоку:

- як індивідуальних теплових джерел, тобто випадок відсутності накладення температурних полів від сусідніх іонів та електронів ( $j \leq j^{\prime}{ }_{\text {кр }}$ );

- спільну теплову дію ряду частинок при накладенні їх температурних полів $(j \leq j$ ’ $\leq$ $\left.j{ }^{\prime \prime}{ }_{k p}\right)$;

- дія плазмового потоку як суцільного середовища $\left(j \geq j{ }^{\prime \prime}{ }^{\prime}\right)$.

Найбільш цікавий випадок при дії електронів та іонів середніх енергій в плазмовому потоці за умови, що $j \leq j$ ' критичною, тобто коли спостерігається накладення температурних полів від дії сусідніх частинок, завдання ускладнюється, тому воно і розглядалось. Показано, щяо при дії іонів азоту на сталь реалізується значна область з наноструктурами, тоді як при дії іонів титану на алюмінісвий сплав ия зона обмежена. При дї електронів наноструктури не утворюються, температурні напруження в обох випадках мають значення порядку $10^{8}$ $H / \mathrm{M}^{2}$, вони теж не дають можливості отримувати наноструктури безпосередньо, тоді як можуть прискорити їх отримання. Показано, щяо досягаються необхідні температури $i$ швидкості наростання температур, величини температурних напружень (тисків) достатні для отримання наноструктур в об'ємі деталі, в той же час для підвищення ефективності иього процесу можна подавати в плазмовому поточі невелику частку іонів каталізатора. Показано, ще при впливі іонів азоту на сталь реалізується значна область $з$ наноструктурами, а при впливі іонів титану на алюмінієвий сплав ия зона обмежена. Під дією електронів наноструктури не утворюються, температурні напруження в обох випадках мають значення порядку $10^{8} \mathrm{H} / \mathrm{M}^{2}$, вони також не дозволяють отримувати наноструктури безпосередньо, хоча можуть прискорити їх утворення в температурному інтервалі і темп їх зростання.
\end{abstract}

Ключові слова: наноструктуровані шари; температурні поля; температурні напруження; нанокластери; розмір зерна; спільна проблема теплопровідності та термопружності. 